\title{
Advances in the management of atrial fibrillation
}

\author{
Anthony Li and Elijah R Behr
}

\begin{abstract}
Atrial fibrillation (AF) is the most common arrhythmia worldwide, increasing in incidence with the aging population. Substantial morbidity and mortality accompany its diagnosis. Management should focus on rate and rhythm management, on reducing thromboembolic risk, and also potentially on targeting the mechanisms responsible for its perpetuation. Current antiarrhythmic therapy has only modest efficacy and substantial side effects, and anticoagulation regimes are cumbersome and require regular monitoring. Novel anticoagulants and antiarrhythmics hold the promise of improved efficacy and safety. This review covers current therapy for AF, major advances in pharmacological management and future directions for therapy.
\end{abstract}

KEY WORDS: atrial fibrillation, pharmacotherapy, anticoagulation, antiarrhythmics

\section{Background}

The main goals of management in atrial fibrillation (AF) are to ameliorate symptoms and reduce the risk of adverse sequelae. A combination of strategies to maintain sinus rhythm, control heart rate and reduce thromboembolic risk have been employed. Widespread prescription of antiarrhythmic drugs (AAD) is, however, limited by their proarrhythmic effect and/or their significant extra-cardiac toxicity. ${ }^{1-3}$

The recent expansion of electrophysiology services and catheter ablation techniques has provided modern alternatives to long-term AAD therapy. Ablation has not, however, proven to be a panacea, with disappointing recurrence rates, particularly in persistent $\mathrm{AF}^{4}$ Pharmacotherapy of AF has provided promising progress and as our understanding of pathogenesis evolves, the paradigm has shifted towards preventative therapy.

AF remains the most common arrhythmia worldwide, with an estimated and increasing prevalence of $1-2 \% .{ }^{5,6}$ It is an independent marker for increased mortality and morbidity, carrying a five-fold increased risk of stroke, hospitalisation and/or heart failure. ${ }^{7} \mathrm{AF}$ is divided into sub-types that are based on duration: episodes shorter than seven days are referred to as paroxysmal; persistent AF has episodes that last for more than seven days; and permanent $\mathrm{AF}$ is accepted in the long term.

Anthony Li, cardiology specialist registrar; Elijah R Behr, senior lecturer and honorary consultant cardiologist and electrophysiologist

St George's University of London, UK
The principles of medical management are:

1 assessment of stroke risk and appropriate antithrombotic therapy;

2 treatment of symptoms with rate or rhythm control; and

3 treatment of underlying disease processes.

\section{Thromboprophylaxis}

\section{Risk stratification}

Antithrombotic therapy for AF is the only treatment consistently associated with a reduction in mortality. Several validated riskstratification scores exist to determine the adjusted annual risk of stroke. Paroxysmal, persistent and permanent AF have similar rates of stroke. The minimum burden of AF required to cause a clinically significant rise in stroke risk is, however, currently unknown. ${ }^{8,9}$ The NICE AF management guidelines published in 2006 used a three-tier risk stratification algorithm, which many found difficult to apply. ${ }^{10}$ The more widely used $\mathrm{CHADS}_{2}$ score (Cardiac failure, Hypertension, Age $\geq 75$, Diabetes, Stroke) assigned one point for each risk factor and two points for previous stroke or transient ischaemic attack (TIA) (Table 1). ${ }^{11,12}$

Anticoagulation was recommended for those with a score of $\geq 2$. The recognition of further risk factors for stroke meant that some patients classified as low risk by the $\mathrm{CHADS}_{2}$ score were still at moderate risk and could benefit from anticoagulation. This lead to the development of the $\mathrm{CHA}_{2} \mathrm{DS}_{2}$-VASc scoring system (Table 2), which identifies truly low risk patients $($ score $=0)$ who do not need thromboprophylaxis. This scoring system has been adopted by the updated European guidelines for those whose original $\mathrm{CHADS}_{2}$ score is $\leq 1 .^{13,14}$

\section{Warfarin}

Dose-adjusted warfarin is currently regarded as the gold standard for stroke prevention. A meta-analysis has demonstrated a clear

\begin{tabular}{|c|c|}
\hline CHADS $_{2}$ score & Adjusted stroke rate $(\% / y r)$ \\
\hline 0 & 1.9 \\
\hline 1 & 2.8 \\
\hline 2 & 4.0 \\
\hline 3 & 5.9 \\
\hline 4 & 8.5 \\
\hline 5 & 12.5 \\
\hline 6 & 18.2 \\
\hline
\end{tabular}

$\mathrm{C}=$ cardiac failure; $\mathrm{H}=$ hypertension; $\mathrm{A}=$ age $>75 ; \mathrm{D}=$ diabetes; $\mathrm{S}=$ stroke or $\mathrm{TIA} ; \mathrm{TIA}=$ transient ischaemic attack. Each is assigned one point except stroke or TIA, which is assigned two points. Adapted from Gage et al. 2011. ${ }^{11}$ 
benefit of warfarin over placebo or no treatment, with a risk reduction of $64 \%$ (95\% confidence interval (CI) 49-74). ${ }^{15}$ Studies also show consistent underuse of warfarin in high-risk patients because of factors such as advanced age and falls, significant bleeding risks (which tend to be overestimated by clinicians ${ }^{16}$ ) and the need for regular monitoring resulting from variability in metabolism and polypharmacy. ${ }^{17-19}$ In contemporary studies, the risk of intracerebral haemorrhage in warfarin-treated patients with atrial fibrillation is $0.7 \%$, with a major bleeding rate of $3.6 \%$ per annum. ${ }^{20}$ The consequences of intracranial bleeding are, however, catastrophic with a $76 \%$ risk of death or significant disability. ${ }^{21}$ Achieving adequate anticoagulation is therefore critical but problematic as the therapeutic index for warfarin is narrow. An analysis of patients receiving 'optimal' warfarin management found them to be in therapeutic range $63 \%$ of the time on average. ${ }^{22}$

Table 2. Association of $\mathrm{CHA}_{2} \mathrm{DS}_{2}-\mathrm{VASc}$ score and stroke rate.

$\mathrm{CHA}_{2} \mathrm{DS}_{2}-\mathrm{VASC}$ Score

0

1

2

3

4

5

6

7

8

9

$C=$ cardiac failure; $A=$ age $65-74 ; A_{2}=$ age $>75$ ( 2 points); $D=$ diabetes; $\mathrm{H}=$ hypertension; $\mathrm{MI}=$ myocardial infarction; $\mathrm{S}_{2}=$ stroke or $\mathrm{TIA}$ (2 points), $\mathrm{SC}=$ sex category (female $=1$ point); $\mathrm{TIA}=$ transient ischaemic attack; $\mathrm{V}=$ vascular disease (prior MI, peripheral vascular disease or aortic plaque). Adapted from Lip et al. $2010 .{ }^{14}$

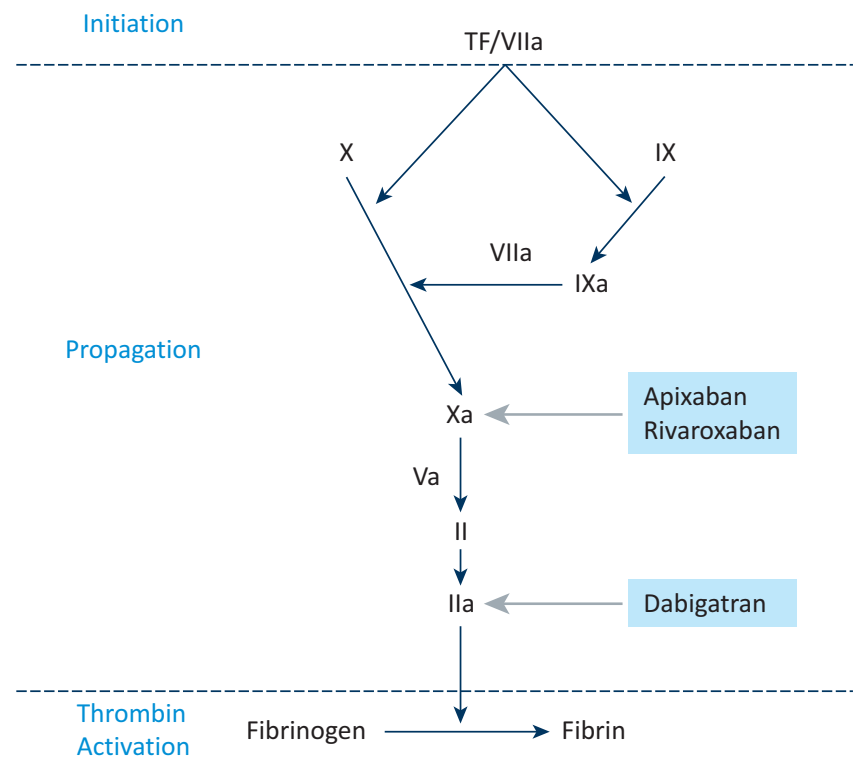

Fig 1. Schematic of the coagulation cascade and mechanism of action of novel anticoagulants.

\section{Aspirin}

Aspirin has long been seen as an alternative to warfarin, but its efficacy in stroke prevention in AF is unconvincing. In Hart et al's meta analysis, aspirin was associated with a non-significant relative risk reduction of $19 \%(\mathrm{CI},-1-35)$ when compared with placebo or no treatment. ${ }^{15}$ A large more recent Danish cohort study found that aspirin had no effect on stroke risk. ${ }^{23}$ By contrast, when aspirin was compared directly to warfarin, warfarin reduced the risk of stroke by just 38\%, which suggests that aspirin might still have a modest effect. In patients aged over 75 years, the benefit of aspirin seems to decline ${ }^{24}$ with no benefit with aspirin over placebo, ${ }^{25}$ and bleeding risks from aspirin are similar to those of warfarin in this group. ${ }^{26}$ Thus, the recommendation for aspirin is likely to be downgraded in future guidelines.

\section{Dual antiplatelet therapy}

The ACTIVE investigators reported two trials that assessed the combination of aspirin and Clopidogrel for stroke prevention in AF. ACTIVE 'W' randomised patients with AF and at least one stroke risk factor into two treatment groups: once receiving dual antiplatelet therapy and the other warfarin. The study was terminated early because of the superiority of warfarin. Importantly, the rates of major bleeding were not significantly different in the two groups. ${ }^{27}$ In the ACTIVE ' $A$ ' trial, patients who were ineligible for warfarin therapy were randomised into a group receiving dual antiplatelet therapy and a group who received aspirin alone. The addition of Clopidogrel significantly reduced the risk of ischaemic stroke from 2.8 to $1.9 \%$ per annum (relative risk (RR) $0.68(0.62-0.83))$ but increased the risk of major bleeding from $1.3 \%$ to $2.0 \%$ (RR $1.57(1.29-1.92)) .{ }^{28}$ Dual antiplatelet therapy could therefore have a role in patients who are unsuitable for warfarin therapy (because of labile coagulation control, as measured by International Normalised Ratio (INR), or patient choice for example) but the associated risk of major bleeding should be considered similar to that of warfarin.

\section{New anticoagulants}

Several new oral anticoagulants have been developed: the direct thrombin inhibitors and the Factor Xa inhibitors (Fig 1). Their advantages rely on a predictable anticoagulant effect with no requirement for monitoring, minimal drug and food interactions and a faster onset and offset of action (Table 3 ). It is likely that future guidelines will be heavily influenced by these new drugs.

\section{Direct thrombin inhibitor: Dabigatran}

Dabigatran is a direct thrombin inhibitor that has recently been approved by NICE for patients with at least one risk factor for stroke, like those recruited to the RE-LY trial. Dabigatran, when 
Table 3. Comparison of the new anticoagulants.

\begin{tabular}{|c|c|c|c|c|c|c|}
\hline Drug & Dose & $\begin{array}{l}\text { Renal } \\
\text { clearance }\end{array}$ & Interactions & $\begin{array}{l}\text { Major bleeding } \\
\text { RR }(95 \% \mathrm{Cl})\end{array}$ & $\begin{array}{l}\text { Stroke or embolism } \\
\text { RR }(95 \% \mathrm{CI})\end{array}$ & $\begin{array}{l}\text { Mortality vs warfarin } \\
\text { RR ( } 95 \% \mathrm{Cl})\end{array}$ \\
\hline \multirow[t]{2}{*}{ Dabigatran } & 100 mg PO BD & \multirow[t]{2}{*}{$80 \%$} & \multirow[t]{2}{*}{ P-gp } & $0.80(0.69-0.93)$ & $0.91(0.74-1.11)$ NS & $0.91(0.80-1.03)$ NS \\
\hline & $150 \mathrm{mg}$ PO BD & & & $0.93(0.81-1.07)$ NS & $0.66(0.53-0.82)$ & $0.88(0.77-1.0)$ NS \\
\hline Rivaroxaban & 20 mg PO OD & $66 \%$ & $\begin{array}{l}\text { P-gp, } \\
\text { CYP450 }\end{array}$ & $1.03(0.89-1.18)$ NS & $0.88(0.75-1.03)$ NS & $0.85(0.70-1.02)$ NS \\
\hline \multirow[t]{2}{*}{ Apixaban } & \multirow[t]{2}{*}{$5 \mathrm{mg}$ PO BD } & \multirow[t]{2}{*}{$25 \%$} & P-gp & $0.70(0.61-0.81)$ & $0.80(0.67-0.92)$ & HR $0.89(0.80-0.99)$ \\
\hline & & & CYP450 & & & \\
\hline
\end{tabular}

$\mathrm{Cl}=$ confidence interval; $\mathrm{BD}=$ twice daily; CYP450 = cytochrome P450 (avoid inducers and inhibitors); NS = not significant; OD = once daily; PO = taken orally; P-gp = permeability glycoprotein system (inhibitors: amiodarone, verapamil, quinidine, ketoconazole, clarithromycin; inducers: rifampicin, St. Johns wort, carbamazepine, phenytoin); RR = relative risk when compared with warfarin treatment for non-valvular AF.

taken at a dose of $150 \mathrm{mg}$ twice daily, was superior to warfarin in reducing the rates of systemic embolism and stroke by $34 \%$, mainly by reducing the rate of haemorrhagic strokes. The bleeding risk associated with the two drugs was comparable overall. Dabigatran at $110 \mathrm{mg}$ twice daily was shown to be noninferior to warfarin and it was associated with a significant $20 \%$ lower rate of bleeding. ${ }^{29}$ Despite these impressive results, concerns have emerged over an unexplained small increase in the risk of myocardial infarction (MI) that was associated with Dabigatran (RR 1.35, CI 0.98-1.87, $\mathrm{p}=0.07$ for $110 \mathrm{mg}$ twice daily; RR 1.38, CI $1-1.91, \mathrm{p}=0.048$ for $150 \mathrm{mg}$ twice daily). Initially, this association was thought to be clinically unimportant, ${ }^{30,31}$ but the risk of MI was highlighted again in a recent meta-analysis of seven heterogeneous randomised trials of Dabigatran: overall risk (OR) 1.33 (95\% CI $1.03-1.71$, $\mathrm{p}=0.03) .{ }^{32}$ Uncertainty remains as existing studies are underpowered to detect a difference in cardiac events and the results could represent a protective effect of warfarin in MI. ${ }^{33}$ Regardless, Dabigatran has a significant net benefit compared with warfarin therapy.

\section{Factor Xa inhibitors}

Rivaroxaban is an oral direct inhibitor of Factor Xa. The ROCKET-AF study was designed as a non-inferiority trial that randomised approximately 14,000 patients with AF and moderate to high risk of stroke (mean CHADS2 score 2.5 ) into treatment groups receiving either a single daily dose of Rivaroxaban $50 \mathrm{mg}$ or dose-adjusted warfarin. Rivaroxaban was non-inferior to warfarin in the intention to treat analysis, producing a non-significant $12 \%$ risk reduction for all strokes and systemic embolism. It resulted in significantly reduced risk of intracranial haemorrhage $(0.5 \%$ vs $0.7 \%)$ and fatal bleeding $(0.2 \%$ vs $0.5 \%)$. Adequate control of anti coagulation by warfarin, as measured by the proportion of time spent in the therapeutic range, was only $55 \%$, substantially less than in other trials of new oral anticoagulants.

Apixaban is another oral direct inhibitor of Factor Xa. The AVERROES study, which randomised patients deemed unsuitable for warfarin to receive twice daily Apixaban or aspirin, was stopped early because of the clear superiority of Apixaban in reducing the relative risk of stroke or systemic embolism by $55 \%$ while maintaining similar rates of major bleeding. ${ }^{34}$ Following from this, ARISTOLE compared twice-daily Apixaban $5 \mathrm{mg}$ against warfarin. Apixaban was superior to warfarin, producing a significant $21 \%$ reduction in any stroke and systemic embolism; as with Dabigatran, this reduction was due to a significant reduction in haemorrhagic strokes. Furthermore, Apixaban reduced all-cause mortality by $11 \%$, a first amongst the new oral anticoagulants. In terms of major bleeding, Apixaban proved superior to warfarin, being associated with significantly less major bleeding and, unlike Dabigatran and Rivaroxaban, no increase in gastrointestinal bleeding. ${ }^{35}$

\section{Disadvantages and uncertainties of the new oral anticoagulants}

Despite their obvious advantages, concerns have been expressed over the new oral anticoagulants. Primarily, the unease results from an inability to measure anticoagulation effect reliably and from the lack of a routine antidote in emergency situations. It has also been argued that their shorter half-life might disadvantage poorly compliant patients in whom a lack of monitoring could play a role. ${ }^{36}$

In addition, these large phase 3 trials were performed in a selected population, and several unanswered questions remain over their applicability to the wider population. The elderly population of older than 80 years were not well represented, and this could be important as the incidence of AF, risk of bleeding and comorbidity all increase with age. All new oral anticoagulants have varying degrees of renal metabolism and insufficient data exist to confirm their safety (at either full or reduced doses) in patients with severe renal disease. ${ }^{37,38}$ Uncertainty remains as to how the new anticoagulants should be used in patients undergoing cardioversion, how patients on therapy who develop acute coronary syndromes should be managed, and how these drugs should be used in patients with mechanical heart valves. It is also uncertain which patients should receive which drug; for example, should patients with previous gastrointestinal bleeding be given Apixaban in view of the small risk benefit? It is also difficult to draw 
comparisons between treatments because of differences in trial design and patient populations. Head-to-head comparisons are needed.

\section{Rate versus rhythm control}

The results supported an initial rate control strategy causing an intellectual dilemma given that sinus rhythm is associated with better outcomes than AF. AFFIRM and AF-CHF were two of the largest trials designed to establish outcomes in patients assigned to either rate or rhythm control approaches, and they found that neither strategy provided a survival advantage. ${ }^{39,40}$ The results supported an initial rate-control strategy, causing an intellectual dilemma given that maintenance of sinus rhythm has been associated with better outcomes in AF. The association of increased mortality or lack of benefit with AAD therapy is thought to be due to proarrhythmia or the lack of efficacy in maintaining sinus rhythm. ${ }^{41}$

Current European Society of Cardiology (ESC) guidelines advocate an individualised approach and early discussion with regards to choice of strategy, basing the decision on adequacy of symptom control after concurrent rate control has been instituted and the likelihood of maintaining sinus rhythm. This is influenced by AF type and by the underlying disease processes contributing to the perpetuation of AF, amongst other factors. Although evidence is lacking, a rhythm-control strategy is usually adopted in younger patients (younger than 65 years old) as a first-line treatment. There is increasing recognition of a window of opportunity for early intervention to alter the progression from paroxysmal to permanent $\mathrm{AF}^{42}$

\section{Rate control}

The definition of adequate rate control has been based historically upon arbitrary definitions set by clinical trials (a resting heart rate of less than $80 \mathrm{bpm}$ in AFFIRM and less than $100 \mathrm{bpm}$

Atrial fibrillation

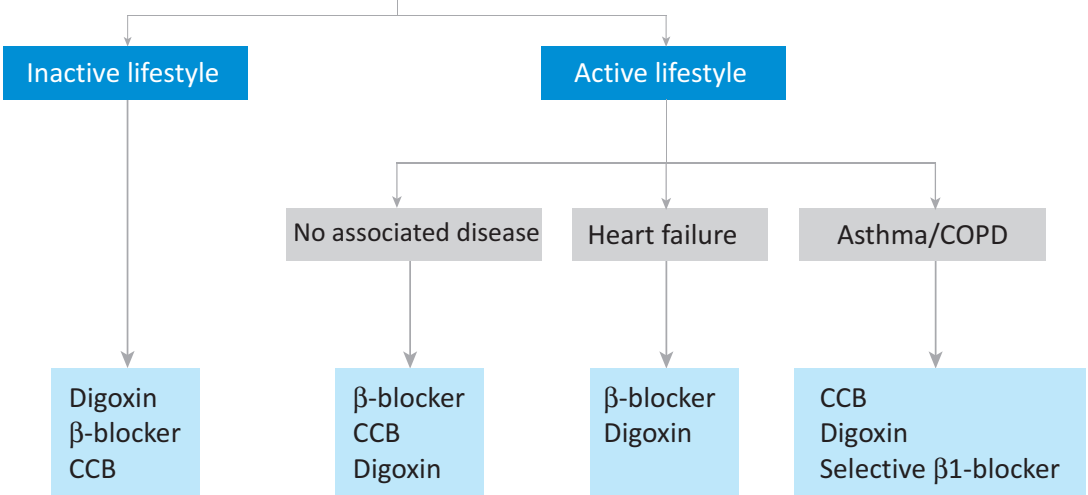

Fig 2. Rate control algorithm. $C C B=$ non-dihydropyridine calcium channel antagonist such as Diltiazem or Verapamil; COPD = chronic obstructive pulmonary disease. Adapted from the 2010 ESC guidelines for the management of $\mathrm{AF}^{7}$ in RACE) and has been the subject of debate. ${ }^{39,43}$ Recently, the RACE II trial results suggest that lenient rate control $(<110 \mathrm{bpm}$ at rest) was not inferior to strict rate control ( $<80 \mathrm{bpm}$ at rest) in controlling AF symptoms. The heart rates achieved in the two arms of this study were, however, similar and the patients were comparatively well with only a short period of follow up. ${ }^{44}$ In addition to symptom control, rate control is necessary to prevent tachycardia-induced cardiomyopathy, but we do not yet know what rate and chronicity are required for tachycardia cardiomyopathy to occur and what its risk factors are. Limited data have indicated that left ventricular function improves mostly within 3-6 months of effective rate control, but improvements can continue at a slower rate for up to a year. Recurrent tachycardia can cause a rapid decline in function and might be a risk for sudden death. ${ }^{45,46}$

Current drugs for rate control have changed little and include beta-blockers and non-dihydropyridine calcium channel blockers (Verapamil and Diltiazem) and Digoxin. They can be used safely in the absence of pre-excitation. The choice of drug should be guided by individual lifestyle and underlying disease (Fig 2). Combinations might be necessary to achieve adequate control; for example, Digoxin could be taken alongside either a beta-blocker or a calcium-channel blocker. ${ }^{47}$ The combination of a betablocker with Verapamil is not routinely used in view of the risk of heart block and hypotension. In view of its extra-cardiac effects, the use of Amiodarone for rate control should be limited to specific patients for whom conventional measures are ineffective or contraindicated. Antithrombotic treatment should also be scrutinised as Amiodarone might lead to inadvertent cardioversion.

\section{New drugs for rate control}

The development of drugs purely for controlling heart rate has halted over the past few years. The most promising agents were the selective Adenosine A1 blockers, which have a selective dromotropic effect on the AV node without the side effects associated with Adenosine. Tecadenoson was tested in a phase 2 trial in patients, but further progress was halted because of unreported side effects. ${ }^{48}$

\section{Rhythm control}

AAD usage is limited primarily by their proarrhythmic side effects, but these drugs can be used safely in selected patient groups with regular monitoring. The current ESC guidelines (Fig 3) are notable for the inclusion of the novel AAD Dronedarone. In contrast to the NICE guidelines, the ESC guidelines do not suggest the use of beta-blockers as first-line agents for rhythm control, as their effect on the maintenance of sinus rhythm is minimal unless it is clearly driven adrenergically. ${ }^{49,50}$

The choice of first-line agents is determined by the underlying heart disease. Amiodarone is 
the only agent suggested for unstable patients who have New York Heart Association category 2 (NYHA 2) or NYHA 3-4 heart failure. With the exception of Sotalol in stable coronary artery disease, all other commonly used AADs mentioned in the ESC guidelines are contraindicated by significant underlying heart disease. Although Dronedarone is only contraindicated in unstable NYHA 2 or NYHA 3-4 heart failure, recent evidence has emerged that is likely to prompt its re-evaluation.

In general, AADs have only modest effects in maintaining sinus rhythm. In a meta-analysis of $44 \mathrm{AAD}$ trials, ${ }^{51}$ when compared to placebo, AADs as a whole reduced the recurrence of $\mathrm{AF}$ by $30-50 \%$ in patients post cardioversion. Amiodarone was the most effective drug; class la agents (Quinidine and Disopyramide) had significant drawbacks of proarrhythmia and increased mortality. ${ }^{51}$ Despite Amiodarone's efficacy in maintaining sinus rhythm and its relative safety in the presence of structural heart disease, guidelines have suggested that it should be used only when all other therapies have failed or are contraindicated (Fig 3). Its serious side effects (thyrotoxicosis, liver and pulmonary toxicity) occur not infrequently, and the combination of these plus more common side effects such as hypothyroidism, photosensitivity and skin discolouration leads to significant discontinuation rates of up to $70 \%$ after five years. ${ }^{52,53}$ Extracardiac side effects should be screened for by 6-monthly thyroid and liver function testing with a low index of suspicion for adverse pulmonary events.

Regardless of which AAD is chosen, the initiation of therapy should always be accompanied by monitoring of QRS duration, QT interval and bradycardia. If the QTc interval approaches or exceeds $500 \mathrm{~ms}$ or if the QRS duration exceeds 120\% of baseline, then therapy should be discontinued. In addition, monitoring of renal function and electrolytes is necessary, particularly with

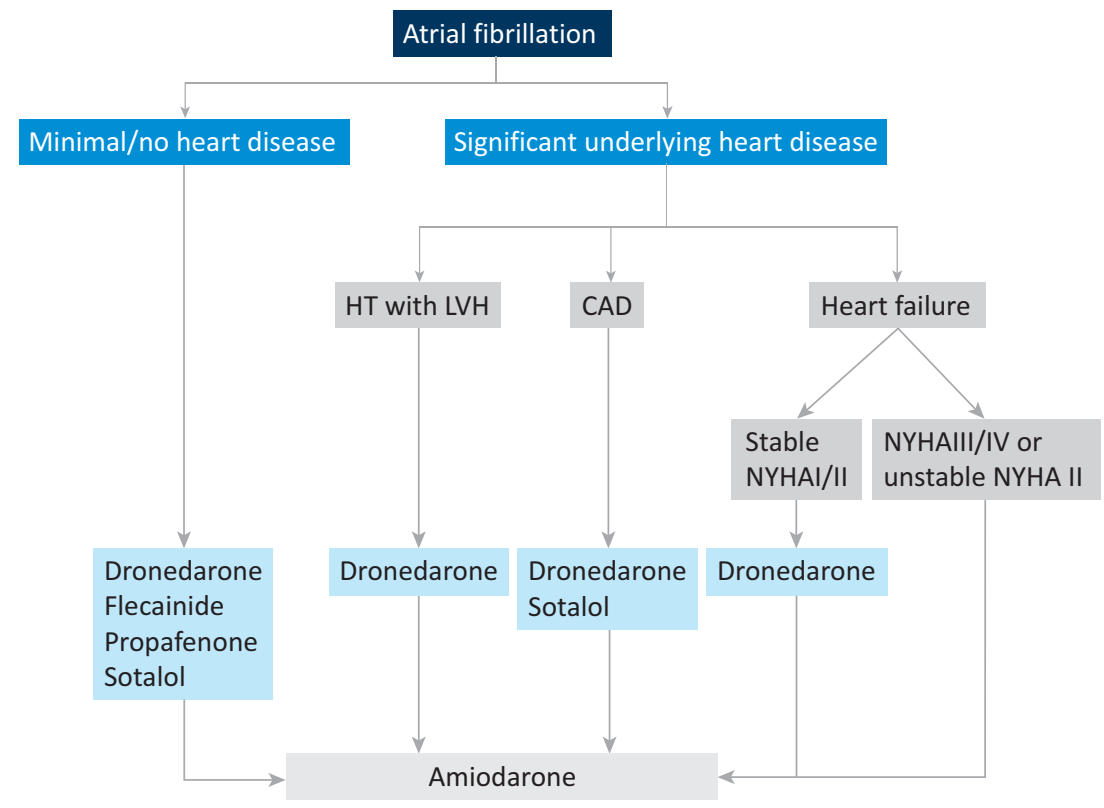

Fig 3. Rhythm control algorithm. $C A D=$ coronary artery disease; $H T=$ hypertension; $\mathrm{LVH}=$ left ventricular hypertrophy; NYHA = New York Heart Association. Adapted from the 2010 ESC guidelines for the management of $\mathrm{AF}^{7}$
Flecainide and Sotalol as the risk of proarrhythmia might be increased by these drugs (Table 4$).{ }^{54}$

\section{Dronedarone}

Dronedarone is a benzofuran derivative multichannel blocker, similar to amiodarone but lacking the iodine moiety. It is not prone, however, to induce thyroid, neurological, ocular or dermatological adverse events. There are insufficient data to determine the potential for pulmonary or liver toxicities that might be associated with this drug and so regular monitoring is suggested by the European Medicines Agency (EMA). ${ }^{55}$ In the DIONYSOS trial, the antiarrhythmic efficacy of Dronedarone was inferior to that of Amiodarone with a recurrence of AF of $64 \%$ vs $42 \%$ at one year post cardioversion. ${ }^{56}$ Although direct head-to-head comparisons are lacking, the efficacy of Dronedarone is likely to be similar to those of Sotalol and other Class $1 \mathrm{c}$ agents. ${ }^{51,57}$

Clinical trials involving Dronedarone have shown both promising and concerning results. Dronedarone was associated with a doubling of mortality rate compared to placebo in patients without AF who were hospitalised for decompensated heart failure and an ejection fraction (EF) $<35 \%$ in the ANDROMEDA trial. ${ }^{58}$ The ATHENA trial excluded patients with NYHA IV heart failure, with only $3.9 \%$ of the 4,000 patients having an $\mathrm{EF}<35 \%$. For the first time, an $\mathrm{AAD}$ for $\mathrm{AF}$ significantly reduced hospitalisation and cardiovascular death; in this case by $24 \% .^{59}$

On the basis of these results, Dronedarone was incorporated into the updated ESC guidelines and, in 2010, NICE released a technology appraisal on Dronedarone that recommended its use in a selected group of patients mirroring the inclusion criteria for the ATHENA trial: ${ }^{60}$ a second-line therapy in non-permanent AF without NYHA 3-4 heart failure AND at least one of Hypertension on more than two drugs; diabetes; previous TIA, stroke or systemic embolism; left atrial diameter greater than $5 \mathrm{~cm}$; left ventricular ejection fraction (LVEF) 35-40\%; or age $\geq 70$.

The more recent PALLAS trial randomised approximately 3,000 high-risk permanent AF patients to receive either Dronedarone or placebo in addition to standard therapy. This trial included patients with coronary disease, symptomatic heart failure (NYHA class 2-3) and admission to hospital in the previous year, EF $<40 \%$, or major risk factors for heart disease. The study was terminated early because of a significant increase in stroke, heart failure and death associated with Dronedarone (HR 2.11, CI 1.34-3.94), mostly due to arrhythmia. ${ }^{61}$ In light of these findings, the EMA issued a report recommending that Dronedarone should not be given to patients with left ventricular (LV) systolic dysfunction or with current or previous 
Table 4. Commonly prescribed antiarrhythmic drugs for the maintenance of sinus rhythm.

\begin{tabular}{|c|c|c|c|}
\hline Drug & Dose & Renal disease & $\begin{array}{l}\text { OR for AF recurrence at one year vs control } \\
\text { (Peto OR-fixed effects) }^{*}\end{array}$ \\
\hline Dronedarone & $400 \mathrm{mg} \mathrm{BD}$ & $\mathrm{Cl}$ if $\mathrm{CrCl}<30 \mathrm{mg} / \mathrm{ml}$ & $0.60(0.47-0.77)$ \\
\hline Sotalol & $80-160 \mathrm{mg}$ BD & $\begin{array}{l}\mathrm{Cl} \text { if } \mathrm{CrCl}<50 \mathrm{mg} / \mathrm{ml} \text {, requires dose adjustment } \\
\text { if moderate renal impairment }\end{array}$ & $0.43(0.35-0.53)$ \\
\hline Propafenone & 150-300 mg TDS & Caution in renal impairment & $0.34(0.25-0.44)$ \\
\hline Flecainide & 100-200 mg BD & $\mathrm{Cl}$ if $\mathrm{CrCl}<50 \mathrm{mg} / \mathrm{ml}$ & $0.30(0.16-0.57)$ \\
\hline Amiodarone & $200 \mathrm{mg}$ OD after loading & & $0.19(0.14-0.26)$ \\
\hline
\end{tabular}

episodes of heart failure. ${ }^{55}$ We are therefore likely to see Dronedarone downgraded in subsequent guidelines so that it is used, in line with other AADs, only in patients without structural heart disease.

\section{New drugs for rhythm control}

Amiodarone analogues. Several other Amiodarone analogues are currently in development and have favourable side-effect profiles. Budiodarone has a shorter half-life and less tissue accumulation than Amiodarone. Compared to placebo, it reduced significantly the AF burden by $74 \%$ in patients with dual chamber pacemakers. ${ }^{62}$ Celiverone had been developed without an iodine moiety, but in early studies this drug had no effect on either AF recurrence post cardioversion or rate of cardioversion to sinus rhythm. ${ }^{63}$

Atrial repolarisation-delaying agents. Atrial repolarisation-delaying agents that selectively target atrial ion channels, theoretically reducing the risk of proarrhythmia, are in development. ${ }^{64}$ The most promising agents target the Kv1.5 channel that is responsible for the ultra-rapid delayed rectifier potassium current $\left(\mathrm{I}_{\mathrm{Kur}}\right)$. Many of these agents, such as Vernakalant, which has been licensed in Europe for intravenous acute cardioversion of AF, act on multiple ion channels ( $\mathrm{I}_{\mathrm{Kur}}, \mathrm{I}_{\text {to }}$ and $\left.\mathrm{I}_{\mathrm{Na}}\right)$.

Sodium channel blockers. Ranolazine, which was originally developed for the treatment of angina, is an inhibitor of the late and peak $\mathrm{I}_{\mathrm{Na}}$ current. In the MERLIN-TIMI 36 trial, which compared Ranolazine against placebo in 6,500 patients with nonST-elevation MI, Ranolazine significantly reduced the incidence of new onset AF by $29 \% .{ }^{65}$ It is currently being investigated for its use in maintaining sinus rhythm post cardioversion. ${ }^{66}$

Other novel drugs for rhythm control. More novel AADs are in development, but most have not been tested in humans. These include agents that inhibit $\mathrm{Na} / \mathrm{H}$ exchangers, $\mathrm{I}_{\mathrm{KACH}}$ blockers, Gap-junction modifiers and calcium-handling modifiers. ${ }^{67}$

\section{Pharmacological restoration of sinus rhythm}

In select patients, conversion to sinus rhythm can provide relief from highly symptomatic AF. Patients who are haemodynamically compromised should be electrically cardioverted on an emergent basis. Sinus rhythm can be restored safely provided that the onset of AF is within 48 hours. If the onset is more than 48 hours, anticoagulation within therapeutic range should be ensured for a month prior to attempting restoration of sinus rhythm, or transoesophageal echocardiography should be undertaken to rule out atrial thrombus formation if the need to restore sinus rhythm is judged to be more urgent. Several drugs are available for cardioversion. The choice of agent should be guided by the presence of structural heart disease as class $1 \mathrm{c}$ agents are contraindicated in the presence of such disease. In general, pharmacological cardioversion is achieved more successfully the sooner it is attempted after the onset of AF, with a considerable drop in efficacy of antiarrhythmic agents after seven days.

Flecainide has been shown to be effective in recent onset AF (ie during the first 48 hours), with conversion rates of up to $90 \%$ in some studies. ${ }^{68}$ Oral and iv preparations are equally effective, although iv preparations are more rapid. ${ }^{69}$ Propafenone has similar efficacy. ${ }^{70,71}$ During the first 48 hours after the onset of AF, Amiodarone achieves sinus rhythm within 24 hours in approximately $90 \%$ of patients. ${ }^{72}$

\section{New drugs for the restoration of sinus rhythm}

Vernakalant, an atrial-selective AAD, has demonstrated its superiority against placebo with conversion rates of approximately $50-60 \%$ and a median time to sinus rhythm without proarrythmia of 8-14 minutes. ${ }^{73-75}$ Vernakalant is superior for rapid cardioversion (within 90 minutes) of AF of up to 48-hour duration compared to Amiodarone. In contrast to the class $1 \mathrm{c}$ agents, Vernakalant might also provide a safer alternative in patients with ischaemic heart disease ${ }^{76}$ and post cardiac surgery, ${ }^{77}$ but has not yet been studied in those with other forms of structural heart disease.

\section{Upstream therapies}

$\mathrm{AF}$ is a progressive disease that involves continual atrial electrical and structural remodelling, which perpetuates AF. The factors that contribute to remodelling are an attractive target for primary and secondary prevention. 
The renal angiotensin aldosterone system (RAAS) is thought to be partly responsible for the inflammation, negative remodelling and fibrosis of the atria. Experimental animal models have demonstrated that treatment with angiotensin-converting enzyme inhibitors (ACEi) and aldosterone receptor blockers (ARB) reduces interstitial fibrosis. ${ }^{78}$ Four meta-analyses evaluating ACEi or ARB for the prevention of AF have shown a significant reduction in new onset AF of $18-33 \%$ driven primarily by a $32-48 \%$ reduction in patients with LV systolic dysfunction and/or heart failure. ${ }^{79-82}$ One meta-analysis showed a significant $23 \%$ reduction in new onset $\mathrm{AF}$ in hypertensives. ${ }^{81}$ The evidence for secondary prevention with ACEi or ARB agents is controversial, but their use prior to cardioversion reduced the risk of recurrent AF by $45-51 \% .79,81,82$

There is also a growing interest in targeting inflammation. The pleotropic and anti-inflammatory effects of statins on electrical and structural remodelling have been studied in animal models. ${ }^{83}$ There is no convincing evidence from clinical trials, however, to show that statins can reduce either the onset of new $\mathrm{AF}$ or AF recurrence after cardioversion. When given in the preoperative phase of cardiac surgery (bypass and valve), however, meta-analysis suggests a $34 \%$ reduction in new $\mathrm{AF}^{84}$ Like statins, polyunsaturated fatty acid (PUFA) supplements have been postulated to act via inflammatory pathways, and their effects are supported by convincing data from animal studies. This has not been translated, however, to clinical outcomes in humans. Large clinical trials are underway that may yet support their use. ${ }^{85}$

\section{Conclusions}

$\mathrm{AF}$ has long been recognised as a complex and progressive disease with significant associated morbidity and mortality. Its incidence is increasing in an ageing population. Pharmacological therapies exist and are currently in development to treat thromboembolic risk and to allow the maintenance of sinus rhythm without proarrhythmic or extra-cardiac side effects. There will be imminent changes in the guidelines to incorporate new anticoagulants. Dronedarone has not fulfilled its promise as a 'safer Amiodarone' and its use is likely to be restricted. Upstream therapies are an attractive future prospect but have yet to find robust clinical support in patients without vascular risk factors or structural heart disease. This may represent a failure to predict and hence target those patients most at risk of developing AF. AF is associated with a genetic predisposition and there are families in whom rare genetic mutations have been isolated who display premature disease $^{86}$ It is likely, however, that multiple genetic variants with modest effects contribute to this genetic risk. ${ }^{87}$ Identification of these variants might allow us to target new pathways for the development of upstream therapies.

\section{References}

1 Echt DS, Liebson PR, Mitchell LB et al. Mortality and morbidity in patients receiving encainide, flecainide, or placebo. The Cardiac Arrhythmia Suppression Trial. New Engl J Med 1991;324:781-8.
2 Waldo AL, Camm AJ, deRuyter $\mathrm{H}$ et al. Effect of d-sotalol on mortality in patients with left ventricular dysfunction after recent and remote myocardial infarction. Lancet 1996;348:7-12.

3 Corley SD, Epstein AE, DiMarco JP et al. Relationships between sinus rhythm, treatment, and survival in the Atrial Fibrillation Follow-Up Investigation of Rhythm Management (AFFIRM) Study. Circulation 2004;109:1509-13.

4 Sorgente A, Tung P, Wylie J, Josephson ME. Six year follow-up after catheter ablation of atrial fibrillation: a palliation more than a true cure. Am J Cardiol 2012;109:1179-86.

5 Go AS, Hylek EM, Phillips KA et al. Prevalence of diagnosed atrial fibrillation in adults: national implications for rhythm management and stroke prevention: the AnTicoagulation and Risk Factors in Atrial Fibrillation (ATRIA) Study. JAMA 2001;285:2370-5.

6 Miyasaka Y, Barnes ME, Gersh BJ et al. Secular trends in incidence of atrial fibrillation in Olmsted County, Minnesota, 1980 to 2000, and implications on the projections for future prevalence. Circulation 2006;114:119-25.

7 Camm AJ, Kirchhof P, Lip GYH et al. Guidelines for the management of atrial fibrillation: the Task Force for the Management of Atrial Fibrillation of the European Society of Cardiology (ESC). Eur Heart J 2010;31:2369-429.

8 Nieuwlaat R, Dinh T, Olsson SB et al. Should we abandon the common practice of withholding oral anticoagulation in paroxysmal atrial fibrillation? Eur Heart J 2008;29:915-22.

9 Stöllberger C, Chnupa P, Abzieher C et al. Mortality and rate of stroke or embolism in atrial fibrillation during long-term follow-up in the embolism in left atrial thrombi (ELAT) study. Clin Cardiol 2004;27:40-6.

10 National Collaborating Centre for Chronic Conditions. Atrial fibrillation: national clinical guideline for management in primary and secondary care. London: Royal College of Physicians, 2006.

11 Gage BF, Waterman AD, Shannon W et al. Validation of clinical classification schemes for predicting stroke: results from the National Registry of Atrial Fibrillation. JAMA 2001;285:2864-70.

12 Fuster V, Rydén LE, Cannom DS et al. ACC/AHA/ESC 2006 guidelines for the management of patients with atrial fibrillation: a report of the American College of Cardiology/American Heart Association Task Force on practice guidelines and the European Society of Cardiology Committee for Practice Guidelines (Writing Committee to Revise the 2001 guidelines for the management of patients with atrial fibrillation) developed in collaboration with the European Heart Rhythm Association and the Heart Rhythm Society. Europace 2006;8:651-745.

13 Lip GYH, Nieuwlaat R, Pisters R et al. Refining clinical risk stratification for predicting stroke and thromboembolism in atrial fibrillation using a novel risk factor-based approach: the euro heart survey on atrial fibrillation. Chest 2010;137:263-72.

14 Lip GYH, Frison L, Halperin JL, Lane DA. Identifying patients at high risk for stroke despite anticoagulation: a comparison of contemporary stroke risk stratification schemes in an anticoagulated atrial fibrillation cohort. Stroke 2010;41:2731-8.

15 Hart RG, Pearce LA, Aguilar MI. Meta-analysis: antithrombotic therapy to prevent stroke in patients who have nonvalvular atrial fibrillation. Ann Intern Med 2007;146:857-67.

16 Man-Son-Hing M, Laupacis A. Anticoagulant-related bleeding in older persons with atrial fibrillation: physicians' fears often unfounded. Arch Intern Med 2003;163:1580-6.

17 Gladstone DJ, Bui E, Fang J et al. Potentially preventable strokes in high-risk patients with atrial fibrillation who are not adequately anticoagulated. Stroke 2009;40:235-40.

18 Ogilvie IM, Newton N, Welner SA, Cowell W, Lip GYH. Underuse of oral anticoagulants in atrial fibrillation: a systematic review. Am J Med 2010;123:638-45.

19 Fang MC, Go AS, Chang Y et al. Warfarin discontinuation after starting warfarin for atrial fibrillation. Circ Cardiovasc Qual Outcomes 2010;3:624-31. 
20 Gallego P, Roldán V, Torregrosa JM et al. Relation of the HAS-BLED bleeding risk score to major bleeding, cardiovascular events and mortality in anticoagulated patients with atrial fibrillation. Circ Arrhythm Electrophysiol 2012;5:312-8.

21 Fang MC, Go AS, Chang Y et al. Death and disability from warfarinassociated intracranial and extracranial hemorrhages. Am J Med 2007;120:700-5.

22 Connolly SJ, Pogue J, Eikelboom J et al. Benefit of oral anticoagulant over antiplatelet therapy in atrial fibrillation depends on the quality of international normalized ratio control achieved by centers and countries as measured by time in therapeutic range. Circulation 2008;118:2029-37.

23 Olesen JB, Lip GYH, Lindhardsen J et al. Risks of thromboembolism and bleeding with thromboprophylaxis in patients with atrial fibrillation: a net clinical benefit analysis using a 'real world' nationwide cohort study. Thromb Haemost 2011;106:739-49.

24 van Walraven C, Hart RG, Connolly S et al. Effect of age on stroke prevention therapy in patients with atrial fibrillation: the atrial fibrillation investigators. Stroke 2009;40:1410-6.

25 Preliminary report of the Stroke Prevention in Atrial Fibrillation Study. New Engl J Med 1990;322:863-8.

26 Mant J, Hobbs FDR, Fletcher K et al. Warfarin versus aspirin for stroke prevention in an elderly community population with atrial fibrillation (the Birmingham Atrial Fibrillation Treatment of the Aged Study, BAFTA): a randomised controlled trial. Lancet 2007;370:493-503.

27 Connolly S, Pogue J, Hart R et al. Clopidogrel plus aspirin versus oral anticoagulation for atrial fibrillation in the Atrial fibrillation Clopidogrel Trial with Irbesartan for prevention of Vascular Events (ACTIVE W): a randomised controlled trial. Lancet 2006;367:1903-12.

28 Connolly SJ, Pogue J, Hart RG et al. Effect of clopidogrel added to aspirin in patients with atrial fibrillation. New Engl J Med 2009;360:2066-78.

29 Connolly SJ, Ezekowitz MD, Yusuf S et al. Dabigatran versus warfarin in patients with atrial fibrillation. New Engl J Med 2009;361:1139-51.

30 Connolly SJ, Ezekowitz MD, Yusuf S et al. Newly identified events in the RE-LY trial. New Engl J Med 2010;363:1875-6.

31 Hohnloser SH, Oldgren J, Yang S et al. Myocardial ischemic events in patients with atrial fibrillation treated with dabigatran or warfarin in the RE-LY trial. Circulation 2012;125:669-76.

32 Uchino K, Hernandez AV. Dabigatran association with higher risk of acute coronary events: meta-analysis of noninferiority randomized controlled trials. Arch Intern Med 2012;172:397-402.

33 Smith P, Arnesen H, Holme I. The effect of warfarin on mortality and reinfarction after myocardial infarction. New Engl J Med 1990;323: 147-52

34 Connolly SJ, Eikelboom J, Joyner C et al. Apixaban in patients with atrial fibrillation. New Engl J Med 2011;364:806-17.

35 Granger CB, Alexander JH, McMurray JJV et al. Apixaban versus warfarin in patients with atrial fibrillation. New Engl J Med 2011;365: 981-2.

36 Ansell J. New oral anticoagulants should not be used as first-line agents to prevent thromboembolism in patients with atrial fibrillation. Circulation 2012;125:165-70.

37 Gage L. Dabigatran in patients with nonvalvular atrial fibrillation. J Am Coll Cardiol 2011;58:551; author reply 551.

38 Bell S, Nand J, Spriggs D. New antithrombotic drugs for atrial fibrillation: caution is needed. Lancet 2012;379:e24; author reply e24-5.

39 Wyse DG, Waldo AL, DiMarco JP et al. A comparison of rate control and rhythm control in patients with atrial fibrillation. New Engl J Med 2002;347:1825-33.

40 Roy D, Talajic M, Nattel S et al. Rhythm control versus rate control for atrial fibrillation and heart failure. New Engl J Med 2008;358:2667-77.

41 Corley SD, Epstein AE, DiMarco JP et al. Relationships between sinus rhythm, treatment, and survival in the Atrial Fibrillation Follow-Up Investigation of Rhythm Management (AFFIRM) study. Circulation 2004;109:1509-13.
42 Camm AJ, Breithardt G, Crijns H et al. Real-life observations of clinical outcomes with rhythm- and rate-control therapies for atrial fibrillation RECORDAF (Registry on Cardiac Rhythm Disorders Assessing the Control of Atrial Fibrillation). J Am Coll Cardiol 2011;58:493-501.

43 Van Gelder IC, Hagens VE, Bosker HA et al. A comparison of rate control and rhythm control in patients with recurrent persistent atrial fibrillation. New Engl J Med 2002;347:1834-40.

44 Van Gelder IC, Groenveld HF, Crijns HJGM et al. Lenient versus strict rate control in patients with atrial fibrillation. New Engl J Med 2010;362:1363-73.

45 Nerheim P, Birger-Botkin S, Piracha L, Olshansky B. Heart failure and sudden death in patients with tachycardia-induced cardiomyopathy and recurrent tachycardia. Circulation 2004;110:247-52.

46 Chin A. What is the time course of reversal of tachycardia-induced cardiomyopathy? Europace 2011;13:763.

47 Farshi R, Kistner D, Sarma JS, Longmate JA, Singh BN. Ventricular rate control in chronic atrial fibrillation during daily activity and programmed exercise: a crossover open-label study of five drug regimens. J Am Coll Cardiol 1999;33:304-10.

48 Safety Study of Tecadenoson to Treat Atrial Fibrillation, 2008. http://clinicaltrials.gov/ct2/show/NCT00713401 [Accessed Feb 2012].

49 Nergårdh AK, Rosenqvist M, Nordlander R, Frick M. Maintenance of sinus rhythm with metoprolol CR initiated before cardioversion and repeated cardioversion of atrial fibrillation: a randomized doubleblind placebo-controlled study. Eur Heart J 2007;28:1351-7.

50 Kühlkamp V, Schirdewan A, Stangl K et al. Use of metoprolol CR/XL to maintain sinus rhythm after conversion from persistent atrial fibrillation: a randomized, double-blind, placebo-controlled study. J Am Coll Cardiol 2000;36:139-46.

51 Lafuente-Lafuente C, Mouly S, Longás-Tejero MA et al. Antiarrhythmic drugs for maintaining sinus rhythm after cardioversion of atrial fibrillation: a systematic review of randomized controlled trials. Arch Intern Med 2006;166:719-28.

52 Roy D, Talajic M, Dorian P et al. Amiodarone to prevent recurrence of atrial fibrillation. Canadian Trial of Atrial Fibrillation Investigators. New Engl J Med 2000;342:913-20.

53 Kim MH, Smith PJ, Jhaveri M et al. One-year treatment persistence and potential adverse events among patients with atrial fibrillation treated with amiodarone or sotalol: a retrospective claims database analysis. Clin Ther 2011;33:1668-81.

54 Sullivan SD, Orme ME, Morais E, Mitchell SA. Interventions for the treatment of atrial fibrillation: A systematic literature review and meta-analysis. Int J Cardiol 2012; [Epub ahead of print]

55 European Medicines Agency. Assessment report for MULTAQ - EMEA/ H/C/1043/A-20/005, 2012.

56 Le Heuzey J-Y, De Ferrari GM, Radzik D et al. A short-term, randomized, double-blind, parallel-group study to evaluate the efficacy and safety of dronedarone versus amiodarone in patients with persistent atrial fibrillation: the DIONYSOS study. J Cardiovasc Electrophysiol 2010;21:597-605.

57 Freemantle N, Lafuente-Lafuente C, Mitchell S et al. Mixed treatment comparison of dronedarone, amiodarone, sotalol, flecainide, and propafenone, for the management of atrial fibrillation. Europace 2011;13:329-45.

58 Køber L, Torp-Pedersen C, McMurray JJV et al. Increased mortality after dronedarone therapy for severe heart failure. New Engl J Med 2008;358:2678-87.

59 Hohnloser SH, Crijns HJGM, van Eickels M et al. Effect of dronedarone on cardiovascular events in atrial fibrillation. New Engl J Med 2009;360:668-78.

60 National Institute for Health and Clinical Excellence. Dronedarone for the treatment of non-permanent atrial fibrillation-TA197. London: NICE, 2010.

61 Connolly SJ, Camm AJ, Halperin JL et al. Dronedarone in high-risk permanent atrial fibrillation. New Engl J Med 2011;365:2268-76. 
62 Ezekowitz MD, Nagarakanti R, Lubinski A et al. A randomized trial of budiodarone in paroxysmal atrial fibrillation. J Interv Card Electrophysiol 2011;34:1-9.

63 Khitri AR, Aliot EM, Capucci A et al. Celivarone for maintenance of sinus rhythm and conversion of atrial fibrillation/flutter. J Cardiovasc Electrophysiol 2012;23:462-72.

64 Jacob S, Ali OA, Pidlaoan V et al. Pharmacotherapy of atrial fibrillation: a pathophysiological perspective and review. Am J Ther 2011;18:241-60.

65 Scirica BM, Morrow DA, Hod $\mathrm{H}$ et al. Effect of ranolazine, an antianginal agent with novel electrophysiological properties, on the incidence of arrhythmias in patients with non ST-segment elevation acute coronary syndrome: results from the Metabolic Efficiency With Ranolazine for Less Ischemia in Non ST-Elevation Acute Coronary Syndrome Thrombolysis in Myocardial Infarction 36 (MERLIN-TIMI 36) randomized controlled trial. Circulation 2007; 116:1647-52.

66 Ranolazine in Atrial Fibrillation Following An ELectricaL CardiOversion (RAFFAELLO), 2012. http://clinicaltrials.gov/ct2/show/ NCT01534962?term =ranolazine\&rank=1 [Accessed Feb 2012]

67 Govindan M, Savelieva I, Catanchin A, Camm AJ. Atrial fibrillationthe final frontier. J Cardiovasc Pharmacol Ther 2010;15(4 Suppl):36S-50S.

68 Martínez-Marcos FJ, García-Garmendia JL, Ortega-Carpio A et al. Comparison of intravenous flecainide, propafenone, and amiodarone for conversion of acute atrial fibrillation to sinus rhythm. Am J Cardiol 2000;86:950-3.

69 Khan IA. Oral loading single dose flecainide for pharmacological cardioversion of recent-onset atrial fibrillation. Int J Cardiol 2003;87:121-8.

70 Boriani G, Biffi M, Capucci A et al. Conversion of recent-onset atrial fibrillation to sinus rhythm: effects of different drug protocols. Pacing Clin Electrophysiol 1998;21(11 Pt 2):2470-4.

71 Khan IA. Single oral loading dose of propafenone for pharmacological cardioversion of recent-onset atrial fibrillation. J Am Coll Cardiol 2001;37:542-7.

72 Bash LD, Buono JL, Davies GM et al. Systematic review and metaanalysis of the efficacy of cardioversion by vernakalant and comparators in patients with atrial fibrillation. Cardiovasc Drugs Ther 2012;26:167-79.

73 Roy D, Rowe BH, Stiell IG et al. A randomized, controlled trial of RSD1235, a novel anti-arrhythmic agent, in the treatment of recent onset atrial fibrillation. J Am Coll Cardiol 2004;44:2355-61.

74 Roy D, Pratt CM, Torp-Pedersen C et al. Vernakalant hydrochloride for rapid conversion of atrial fibrillation: a phase 3, randomized, placebocontrolled trial. Circulation 2008;117:1518-25.
75 Pratt CM, Roy D, Torp-Pedersen C et al. Usefulness of vernakalant hydrochloride injection for rapid conversion of atrial fibrillation. Am J Cardiol 2010;106:1277-83.

76 Torp-Pedersen C, Camm AJ, Butterfield NN et al. Vernakalant: conversion of atrial fibrillation in patients with ischemic heart disease. Int J Cardiol 2011 [Epub ahead of print].

77 Kowey PR, Dorian P, Mitchell LB et al. Vernakalant hydrochloride for the rapid conversion of atrial fibrillation after cardiac surgery: a randomized, double-blind, placebo-controlled trial. Circ Arrhythm Electrophysiol 2009;2:652-9.

78 Savelieva I, Kakouros N, Kourliouros A, Camm AJ. Upstream therapies for management of atrial fibrillation: review of clinical evidence and implications for European Society of Cardiology guidelines. Part I: primary prevention. Europace 2011;13:308-28.

79 Healey JS, Baranchuk A, Crystal E et al. Prevention of atrial fibrillation with angiotensin-converting enzyme inhibitors and angiotensin receptor blockers: a meta-analysis. J Am Coll Cardiol 2005;45:1832-9.

80 Anand K, Mooss AN, Hee TT, Mohiuddin SM. Meta-analysis: inhibition of renin-angiotensin system prevents new-onset atrial fibrillation. Am Heart J 2006;152:217-22.

81 Jibrini MB, Molnar J, Arora RR. Prevention of atrial fibrillation by way of abrogation of the renin-angiotensin system: a systematic review and meta-analysis. Am J Ther 15:36-43.

82 Schneider MP, Hua TA, Böhm M et al. Prevention of atrial fibrillation by renin-angiotensin system inhibition a meta-analysis. J Am Coll Cardiol 2010;55:2299-307.

83 Savelieva I, Camm AJ. Statins and atrial fibrillation: do we need a further study? Expert Rev Cardiovasc Ther 2011;9:801-4.

84 Liakopoulos OJ, Choi Y-H, Kuhn EW et al. Statins for prevention of atrial fibrillation after cardiac surgery: a systematic literature review. $J$ Thorac Cardiovasc Surg 2009;138:678-86.

85 Camm AJ, Savelieva I. Fish oil for secondary prevention of atrial fibrillation: should we still believe in its antiarrhythmic effect? Circulation 2011;124:1093-6.

86 Cunha SR, Hund TJ, Hashemi S et al. Defects in ankyrin-based membrane protein targeting pathways underlie atrial fibrillation. Circulation 2011;124:1212-22.

87 Ellinor PT, Lunetta KL, Albert CM et al. Meta-analysis identifies six new susceptibility loci for atrial fibrillation. Nature Genet 2012;44:670-5.

Address for correspondence: Dr ER Behr, Cardiovascular Sciences Research Centre, St George's University of London, London SW17 ORE. Email: ebehr@sgul.ac.uk 